\title{
Vulnerabilidade sobre duas rodas: tendência e perfil demográfico da mortalidade decorrente da violência no trânsito motociclístico no Brasil, 2004-2014
}

\author{
Two-wheeled vulnerability: trend and demographic profile \\ of mortality caused by motorcycle traffic violence in Brazil, 2004-2014
}

\author{
Marcelo Moreira Corgozinho', Miguel Ângelo Montagner ${ }^{1}$, \\ Maria Augusta Carvalho Rodrigues ${ }^{2}$
}

\begin{abstract}
Resumo
Objetivo: Analisar a tendência de mortalidade entre motociclistas perante os acidentes de transportes e traçar o perfil demográfico das vítimas. Método: Estudo de série histórica que busca avaliar a variação média dos óbitos entre motociclistas nas macrorregiões brasileiras; correlação entre óbitos e a frota circulante; taxas brutas e padronizadas da mortalidade segundo faixa etária, sexo, etnia, escolaridade e acidente de trabalho. Resultados: Observou-se aumento significativo na tendência de mortalidade entre motociclistas nas macrorregiões brasileiras ( $p$-valor $<0,001$ ). Pela apreciação das taxas brutas e padronizadas de mortalidade entre motociclistas, é possível afirmar que os óbitos concentram-se nas macrorregiões Centro-Oeste, Nordeste e Norte. O perfil predominante foi homem jovem, pardo e com baixa escolaridade. Os acidentes de trabalho foram ignorados (57\% a 70\%) das notificações. Observou-se forte correlação entre o aumento da frota circulante e o incremento nas taxas de óbitos entre motociclistas no Brasil $(0,981 ; p<0,001)$. Conclusão: Trata-se de um crescente problema de saúde pública, que acomete principalmente jovens em vulnerabilidade social. A massificação da frota e o aumento do agravo remetem à responsabilidade do Estado em estabelecer ações intersetoriais que reduzam a vulnerabilidade sobre duas rodas.
\end{abstract}

Palavras-chave: motocicleta; mortalidade; acidentes de trânsito; saúde pública.

\begin{abstract}
Objective: To analyze mortality trend among motorcyclists caused by traffic accidents, and to analyze the demographic profile of the victims. Method: This study is a historical series which aims to evaluate the average variation of deaths among motorcyclists in the Brazilian macro-regions; correlation between deaths and the circulating fleet; raw and standardized mortality rates calculated according to age, gender, race, schooling, and work accident. Results: A significantly increase on mortality trend was observed among motorcyclists in the Brazilian macro-regions ( $p$-value $<0.001$ ). Based on the raw and standardized mortality rates among motorcyclists, it is possible to state that deaths are concentrated in the Midwest, Northeast and North macro-regions. The predominant victim was the young, brown man with low education level. Work-related accidents were ignored $57-70 \%$ of notifications. The increase in the circulating fleet was strongly related to the increase in death rates among motorcyclists in Brazil $(0.981 ; p<0.001)$. Conclusion: This is a growing problem of public health, which mainly affects young people in social vulnerability. The massification of the fleet and the increase of mortality refer to the responsibility of the State to establish intersectional actions in order to reduce vulnerability of motorcyclists.

Keywords: motorcycle; mortality; traffic-accidents; public health.

${ }^{1}$ Programa de Pós-graduação em Bioética, Universidade de Brasília (UnB) - Brasília (DF), Brasil.

${ }^{2}$ Instituto de Ciências Biológicas, Universidade de Brasília (UnB) - Brasília (DF), Brasil.

Trabalho realizado no Programa de Pós-graduação em Bioética, Universidade de Brasília (UnB) - Brasília (DF), Brasil.

Endereço para correspondência: Marcelo Moreira Corgozinho - Programa de Pós-graduação em Bioética, Faculdade de Ciências da Saúde, Universidade de Brasília (UnB) - Campus Universitário - CP: 04451 - CEP: 70904-970 - Brasília (DF), Brasil - Email: mmcorgozinho@gmail.com

Fonte de financiamento: nenhuma.

Conflito de interesses: nada a declarar.
\end{abstract}

Este é um artigo publicado em acesso aberto (Open Access) sob a licença Creative Commons Attribution, que permite uso, distribuição e reprodução em qualquer meio, sem restrições desde que o trabalho original seja corretamente citado. 


\section{INTRODUÇÃO}

O Global Status Report on Road Safety ${ }^{1}$ destaca que apesar da melhoria dos números em mortes no trânsito ao redor do mundo, 1,25 milhão de pessoas morrem anualmente, em razão de vários tipos de acidentes; entre eles, 90\% ocorreram em países pobres, onde se localizam menos de $49 \%$ dos veículos registrados em todo o mundo.

A história do trânsito no Brasil foi traçada pela adaptação irresponsável das vias e cidades à extrema utilização de veículos motores $^{2}$. O trânsito tornou-se inseguro, principalmente aos cidadãos mais vulneráveis, como motociclistas, pedestres e ciclistas $^{2-4}$.

Apesar de os acidentes de trânsito não serem considerados uma questão especificamente biomédica, aparecem na agenda da saúde pública por causa das expressivas morbimortalidades por causas externas ${ }^{5,6}$. O índice de fatalidade na circulação viária brasileira é considerado um dos mais altos do mundo 7 .

Em relação aos acidentes de trânsito, destaca-se o aumento do número de acidentes envolvendo motocicletas, dado o fato de ser um veículo ágil, econômico, de tamanho e custo reduzidos ${ }^{2,7}$. Em 2011, o Brasil observou um recorde de fabricação e vendas de motocicletas, com destaque para a Região Nordeste, uma das regiões mais vulneráveis socioeconomicamente ${ }^{8}$.

Estudos $^{9,10}$ relatam que as taxas de lesões e danos fatais são maiores entre as vítimas de acidentes envolvendo motocicletas, quando comparadas às vítimas de qualquer outra forma de condução por veículo de transporte. Assim, essa situação de vulnerabilidade em saúde pública está relacionada principalmente entre os jovens em faixa etária produtiva, com alta morbimortalidade - óbitos e lesões incapacitantes - e resulta em grande ônus econômico para o Sistema Único de Saúde (SUS), além da perda de parcela da população produtora de renda no país ${ }^{2,11,12}$.

Este estudo se justifica pelas altas taxas de acidentes de trânsito motociclístico ${ }^{2-4,10,13}$, bem como pela alta probabilidade de sofrer lesões no trânsito motociclístico, que é até trinta vezes maior quando comparada à do automóvel, até noventa vezes maior do que usando ônibus e até vinte vezes maior do que com automóvel, com resultados fatais ${ }^{3,10}$, além do predomínio expressivo de adultos jovens nos acidentes de trânsito ${ }^{2,3,11,12}$. Trata-se de um estudo relacionado à vulnerabilidade em saúde pública, que objetiva analisar a tendência de mortalidade por acidentes envolvendo motociclistas em acidentes de transportes entre 2004 e 2014 no Brasil e traçar o perfil demográfico das vítimas.

\section{MÉTODO}

Trata-se de um estudo de série temporal das taxas de mortalidade de motociclistas traumatizados em acidentes de transporte no Brasil. Os dados secundários foram extraídos do Sistema de Informações sobre Mortalidade (SIM) do
Departamento de Informática do Sistema Único de Saúde (Datasus) $^{14}$, entre 2004 e 2014.

Para o cálculo das taxas de mortalidade por 100 mil habitantes (hab.), foram considerados todos os óbitos registrados com os Códigos V20-V29 da Classificação Estatística Internacional de Doenças, $10^{\mathrm{a}}$ revisão (CID-10) $)^{5}$, que abrangem os óbitos com motocicleta e triciclo. Considerou-se a estimativa populacional do Instituto Brasileiro de Geografia e Estatística (IBGE) enviada ao Tribunal de Contas da União (TCU) ${ }^{15}$.

Foram calculadas as taxas de mortalidade segundo faixa etária, sexo, etnia/cor, escolaridade e acidente de trabalho. Os dados foram analisados segundo as variáveis sociodemográficas: sexo (masculino/feminino), faixa etária (em anos: $<10 ; 10$ a 19; 20 a 29; 30 a 39; 40 a $49 ; 50$ a 59 e $\geq 60$ ), etnia/cor da pele (branca; preta; amarela; parda e indígena), escolaridade (em anos: nenhuma; 1 a $3 ; 4$ a $7 ; 8$ a 11; $\geq 12$ ), além da variável presença de acidente de trabalho (sim, não e ignorado).

Foram incluídos os dados de mortalidade em acidentes de trânsito envolvendo motocicletas, triciclos - condutor e passageiro - e a frota de motocicletas referentes ao período selecionado (de 2004 a 2014). Foram excluídas informações relativas aos dados parciais, bem como de anos anteriores.

Foram estabelecidas a proporção e a variação média entre os óbitos de motociclistas em relação aos óbitos em acidentes de transporte em cada macrorregião geográfica. As taxas brutas de mortalidades entre motociclistas foram comparadas às taxas padronizadas pelo método direto, com base na população brasileira em 2010. O p-valor indicou o comportamento do agravo no período analisado; $\mathrm{p}<0,05$ indica tendência linear significativa ${ }^{16}$.

Para verificar a correlação entre a frota nacional de motocicletas e a mortalidade em acidentes de trânsito motociclístico, foram utilizados os dados da frota nacional do Departamento Nacional de Trânsito (Denatran) ${ }^{17}$. Para a análise da correlação, foi utilizado o coeficiente linear de Pearson, que mede a direção positiva ou negativa da correlação entre duas variáveis quantitativas ${ }^{16}$.

Este estudo dispensa a apreciação por Comitê de Ética em Pesquisa, uma vez que utilizou exclusivamente dados agregados de acesso público.

\section{RESULTADOS}

Em 2004, foram registrados 35.674 óbitos no SIM causados por acidentes de transporte e, entre eles, 5.067 envolviam motociclistas. Em 2014, esse número aumentou para 44.098 óbitos causados por acidentes de transporte, com 12.666 óbitos entre motociclistas. No período entre 2004 e 2014, foram registrados 104.253 óbitos de motociclistas.

Em 2004, a mortalidade envolvendo motocicletas representou $14,2 \%$ de todos os óbitos relativos aos acidentes de transporte. Essa proporção seguiu uma tendência crescente, alcançando 
27,9\% em 2014 (Tabela 1). A tendência linear da mortalidade entre motociclistas aumentou significativamente em todas as macrorregiões brasileiras ( $\mathrm{p}<0,001)$. A proporção de óbitos em acidentes com motocicleta em relação à mortalidade em acidentes de transporte apresentou uma variação média crescente em todas as macrorregiões brasileiras: Nordeste, Norte, Centro-Oeste, Sudeste e Sul.

A análise da taxa bruta de mortalidade entre motociclistas no Brasil foi igual à taxa padronizada pela população de 2010 (2,8 óbitos em 2004 para 6,2 óbitos por 100 mil habitantes em 2014) (Tabela 2). Segundo a comparação da taxa de mortalidade das macrorregiões brasileiras, é possível apresentá-las em ordem decrescente, tanto para os dados brutos quanto para os padronizados: Centro-Oeste, Nordeste, Norte, Sul e Sudeste. Observou-se diferença entre os dados padronizados e brutos apenas para as regiões Norte, Nordeste e Centro-Oeste. No Norte e Nordeste, em quase todos os anos analisados, observou-se taxa padronizada superior à taxa bruta; por exemplo, no Norte, a taxa bruta foi de 3,0 óbitos, em 2004, para 6,7 óbitos por 100 mil habitantes, em 2014, enquanto a taxa padronizada seguiu com 3,3 óbitos, em 2004, para 7,0 óbitos por 100 mil habitantes, em 2014. Já no Centro-Oeste, foi observado o inverso: uma taxa padronizada sutilmente inferior à taxa bruta, tendo essa sido de 4,5 óbitos, em 2004, para 9,0 óbitos por 100 mil habitantes, em 2014, enquanto a taxa padronizada ficou entre 4,4 óbitos, em 2004, e 8,8 óbitos por 100 mil habitantes, em 2014.

Dados da frota de motocicletas mostram um total de 7.123.476 veículos em 2004 para 23.027.875 em 2014. O incremento no número de óbitos por motocicletas possui forte associação com o aumento da frota circulante, conforme coeficiente de Pearson, calculado de acordo com os dados nacionais: igual a 0,981 e $\mathrm{p}<0,001$ (Tabela 3). Associação semelhante foi observada para as todas as macrorregiões geográficas: Norte $(0,990 ; \mathrm{p}<0,001)$,

Tabela 1. Proporção de óbitos envolvendo motocicletas em relação aos acidentes de transporte por região e ano (Brasil, 2004 a 2014 )

\begin{tabular}{|c|c|c|c|c|c|c|}
\hline Ano & Brasil & Norte & Nordeste & Sudeste & Sul & Centro-Oeste \\
\hline 2004 & 14,2 & 18,4 & 20,2 & 9,8 & 14,5 & 15,2 \\
\hline 2005 & 16,4 & 18,9 & 22,4 & 11,3 & 16,7 & 19,7 \\
\hline 2006 & 19,3 & 19,4 & 24,4 & 15,8 & 19,3 & 21,5 \\
\hline 2007 & 21,1 & 21,9 & 25,6 & 17,3 & 21,3 & 25,3 \\
\hline 2008 & 22,8 & 22,2 & 26,6 & 20,5 & 21,4 & 26,0 \\
\hline 2009 & 24,2 & 24,9 & 29,6 & 20,6 & 22,2 & 26,9 \\
\hline 2010 & 24,8 & 24,6 & 30,4 & 20,6 & 22,7 & 28,6 \\
\hline 2011 & 25,8 & 26,4 & 32,4 & 21,3 & 23,7 & 26,8 \\
\hline 2012 & 27,2 & 28,0 & 35,6 & 20,7 & 25,1 & 28,5 \\
\hline 2013 & 27,7 & 31,3 & 35,5 & 21,5 & 23,8 & 28,6 \\
\hline 2014 & 27,9 & 28,5 & 36,1 & 21,7 & 25,4 & 29,0 \\
\hline Variação média & 1,4 & 1,2 & 1,7 & 1,1 & 1,0 & 1,2 \\
\hline $\mathrm{p}$-valor & $<0,001$ & $<0,001$ & $<0,001$ & $<0,001$ & $<0,001$ & $<0,001$ \\
\hline
\end{tabular}

p-valor da estimativa de tendência linear. Fonte: Brasil ${ }^{14}$, Instituto Brasileiro de Geografia e Estatística ${ }^{15}$

Tabela 2. Taxa de mortalidade (bruta e padronizada) por motociclista traumatizado em um acidente de transporte por região e ano do óbito (Brasil, 2004 a 2014)

\begin{tabular}{|c|c|c|c|c|c|c|c|c|c|c|c|c|}
\hline \multirow{2}{*}{$\begin{array}{c}\text { Ano do } \\
\text { óbito }\end{array}$} & \multicolumn{2}{|c|}{ Brasil } & \multicolumn{2}{|c|}{ Norte } & \multicolumn{2}{|c|}{ Nordeste } & \multicolumn{2}{|c|}{ Sudeste } & \multicolumn{2}{|c|}{ Sul } & \multicolumn{2}{|c|}{ Centro-Oeste } \\
\hline & Bruta & Padr. & Bruta & Padr. & Bruta & Padr. & Bruta & Padr. & Bruta & Padr. & Bruta & Padr. \\
\hline 2004 & 2,8 & 2,8 & 3,0 & 3,3 & 3,1 & 3,3 & 1,8 & 1,8 & 3,8 & 3,9 & 4,5 & 4,4 \\
\hline 2005 & 3,2 & 3,2 & 3,3 & 3,5 & 3,7 & 3,9 & 2,1 & 2,1 & 4,3 & 4,4 & 5,6 & 5,5 \\
\hline 2006 & 3,8 & 3,8 & 3,4 & 3,7 & 4,0 & 4,2 & 3,0 & 3,0 & 4,9 & 5,0 & 5,9 & 5,8 \\
\hline 2007 & 4,3 & 4,3 & 3,8 & 4,1 & 4,5 & 4,6 & 3,4 & 3,3 & 5,5 & 5,5 & 6,9 & 6,7 \\
\hline 2008 & 4,6 & 4,6 & 4,1 & 4,5 & 4,7 & 4,8 & 3,9 & 3,9 & 5,5 & 5,6 & 7,5 & 7,4 \\
\hline 2009 & 4,8 & 4,8 & 4,4 & 4,8 & 5,4 & 5,5 & 3,7 & 3,7 & 5,5 & 5,6 & 7,9 & 7,7 \\
\hline 2010 & 5,5 & 5,5 & 5,3 & 5,6 & 6,8 & 6,9 & 4,0 & 4,0 & 6,0 & 6,1 & 8,9 & 8,7 \\
\hline 2011 & 5,8 & 5,8 & 5,8 & 6,1 & 7,3 & 7,5 & 4,2 & 4,2 & 6,2 & 6,3 & 8,2 & 8,0 \\
\hline 2012 & 6,3 & 6,3 & 6,4 & 6,7 & 8,7 & 8,8 & 4,0 & 4,0 & 6,7 & 6,7 & 8,9 & 8,7 \\
\hline 2013 & 6,0 & 5,9 & 6,9 & 7,2 & 8,3 & 8,4 & 3,8 & 3,9 & 5,7 & 5,7 & 8,8 & 8,5 \\
\hline 2014 & 6,2 & 6,2 & 6,7 & 7,0 & 8,8 & 8,8 & 4,0 & 4,0 & 6,1 & 6,1 & 9,0 & 8,8 \\
\hline p-valor & $<0,001$ & $<0,001$ & $<0,001$ & $<0,001$ & $<0,001$ & $<0,001$ & 0,001 & 0,001 & 0,001 & 0,001 & $<0,001$ & $<0,001$ \\
\hline
\end{tabular}

p-valor da estimativa de tendência linear. Fonte: Brasil ${ }^{14}$, Instituto Brasileiro de Geografia e Estatística ${ }^{15}$ 
Tabela 3. Óbitos por motos (número e taxa de mortalidade por 100 mil habitantes) segundo faixa etária e ano (Brasil, 2004 a 2014)

\begin{tabular}{|c|c|c|c|c|c|c|c|c|c|c|c|c|c|c|c|c|}
\hline \multirow[t]{2}{*}{ Ano } & \multicolumn{2}{|c|}{$<10$ anos } & \multicolumn{2}{|c|}{10 a 19 anos } & \multicolumn{2}{|c|}{20 a 29 anos } & \multicolumn{2}{|c|}{30 a 39 anos } & \multicolumn{2}{|c|}{40 a 49 anos } & \multicolumn{2}{|c|}{50 a 59 anos } & \multicolumn{2}{|c|}{$\begin{array}{c}60 \text { anos e } \\
\text { mais }\end{array}$} & \multicolumn{2}{|c|}{ Total $^{\star}$} \\
\hline & $\mathrm{N}^{\mathrm{o}}$ & Taxa & $\mathrm{N}^{\mathrm{o}}$ & Taxa & $\mathrm{N}^{\circ}$ & Taxa & $\mathrm{N}^{\mathrm{o}}$ & Taxa & $\mathrm{N}^{\mathrm{o}}$ & Taxa & $\mathrm{N}^{\circ}$ & Taxa & $\mathrm{N}^{\mathrm{o}}$ & Taxa & $\mathrm{N}^{\mathrm{o}}$ & Taxa \\
\hline 2004 & 19 & 0,1 & 767 & 2,2 & 2124 & 6,3 & 1179 & 4,3 & 581 & 2,6 & 238 & 1,6 & 156 & 1 & 5067 & 2,8 \\
\hline 2005 & 24 & 0,1 & 887 & 2,6 & 2578 & 7,5 & 1341 & 4,9 & 719 & 3,2 & 286 & 1,9 & 157 & 1 & 5996 & 3,2 \\
\hline 2006 & 28 & 0,1 & 1055 & 3,1 & 3078 & 8,9 & 1519 & 5,4 & 935 & 4 & 345 & 2,2 & 230 & 1,4 & 7198 & 3,8 \\
\hline 2007 & 28 & 0,1 & 1183 & 3,4 & 3523 & 10,1 & 1694 & 6 & 1014 & 4,3 & 423 & 2,5 & 247 & 1,4 & 8118 & 4,3 \\
\hline 2008 & 30 & 0,1 & 1356 & 3,9 & 3776 & 10,8 & 1899 & 6,6 & 1075 & 4,4 & 487 & 2,8 & 316 & 1,7 & 8939 & 4,7 \\
\hline 2009 & 50 & 0,2 & 1215 & 3,5 & 3885 & 11,1 & 2027 & 6,9 & 1226 & 5 & 568 & 3,2 & 330 & 1,7 & 9306 & 4,8 \\
\hline 2010 & 48 & 0,1 & 1471 & 4,3 & 4374 & 12,5 & 2438 & 8,1 & 1411 & 5,6 & 687 & 3,7 & 453 & 2,3 & 10894 & 5,6 \\
\hline 2011 & 43 & 0,1 & 1571 & 4,6 & 4399 & 12,6 & 2611 & 8,5 & 1598 & 6,3 & 789 & 4,1 & 469 & 2,3 & 11485 & 5,8 \\
\hline 2012 & 50 & 0,2 & 1698 & 4,9 & 4486 & 12,9 & 2998 & 9,5 & 1849 & 7,2 & 886 & 4,5 & 566 & 2,7 & 12544 & 6,3 \\
\hline 2013 & 43 & 0,1 & 1628 & 4,7 & 4176 & 12,1 & 2809 & 8,7 & 1778 & 6,8 & 959 & 4,7 & 635 & 2,9 & 12040 & 6 \\
\hline 2014 & 50 & 0,2 & 1714 & 5 & 4300 & 12,5 & 3021 & 9,2 & 1884 & 7,1 & 1058 & 5,1 & 628 & 2,7 & 12666 & 6,2 \\
\hline Média & 37,5 & 0,1 & 1322,3 & 3,8 & 3699,9 & 10,7 & 2139,6 & 7,1 & 1279,1 & 5,1 & 611,5 & 3,3 & 380,6 & 1,9 & 9477,5 & 4,9 \\
\hline $\begin{array}{l}\text { IC95\% } \\
\text { média }\end{array}$ & $\begin{array}{c}30,6- \\
44,5\end{array}$ & $\begin{array}{c}0,09- \\
0,14\end{array}$ & $\begin{array}{l}1128,7- \\
1515,9\end{array}$ & $\begin{array}{c}3,28- \\
4,41\end{array}$ & $\begin{array}{l}3229,1- \\
4170,8\end{array}$ & $\begin{array}{l}9,33- \\
11,98\end{array}$ & $\begin{array}{l}1743,7- \\
2535,5\end{array}$ & $\begin{array}{l}6,01- \\
8,15\end{array}$ & $\begin{array}{l}1008,7- \\
1549,4\end{array}$ & $\begin{array}{c}4,20- \\
6,08\end{array}$ & $\begin{array}{c}444,1- \\
778,8\end{array}$ & $\begin{array}{c}2,59- \\
4,01\end{array}$ & $\begin{array}{c}274,7- \\
486,5\end{array}$ & $\begin{array}{l}1,51- \\
2,33\end{array}$ & $\begin{array}{l}7901,7- \\
11053,4\end{array}$ & $\begin{array}{r}4,14- \\
5,59\end{array}$ \\
\hline
\end{tabular}

75 óbitos com faixa etária ignorada; $\mathrm{p}$-valor (teste $\mathrm{F}$ de igualdade das médias do número) $<0,001$; $\mathrm{p}$-valor (teste $\mathrm{F}$ de igualdade das médias das taxas) $<0,001$. Fonte: Brasil ${ }^{14}$, Instituto Brasileiro de Geografia e Estatística ${ }^{15}$

Nordeste $(0,987 ; \mathrm{p}<0,001)$, Centro-Oeste $(0,961 ; \mathrm{p}<0,001)$, Sul $(0,928 ; \mathrm{p}<0,001)$ e Sudeste $(0,891 ; \mathrm{p}<0,001)$.

A taxa de mortalidade entre motociclistas foi crescente entre 2004 e 2014, aumentando de 6,3 óbitos por 100 mil habitantes em 2004 para 12,5 óbitos por 100 mil habitantes em 2014 (Tabela 1). Esses óbitos foram estratificados de acordo com a faixa etária: menor que 10 anos; 10 a 19 anos; 20 a 29 anos; 30 a 39 anos, 40 a 49 anos; 50 a 59 anos e maior que 60 anos (Tabela 3). A faixa etária na qual ocorre a maioria dos óbitos é de 20 a 29 anos para todos os anos em análise. O segundo grupo etário de maior mortalidade em acidentes com motocicleta situa-se na faixa etária de 30 a 39 anos. Assim, os acidentados entre 20 e 39 anos correspondem a mais da metade (17,8 de 32\%) de todos os óbitos envolvendo motocicletas entre os acidentes automobilísticos notificados no Brasil, entre 2004 e 2014, com números crescentes em todas as faixas etárias no decorrer dos anos.

A maioria das vítimas encontra-se entre os homens, com taxa média de $8,8 \%$ ao longo de dez anos, enquanto as mulheres correspondem a apenas $1,0 \%$, de acordo com a taxa de mortalidade entre motociclistas por 100 mil habitantes, entre 2004 e 2014 (Tabela 4).

A cor predominante é parda, de acordo com a média dos dez anos (5,2\%), seguida de branca (4,5\%), preta $(3,0 \%)$, indígena $(2,1 \%)$ e amarela $(1,7 \%)$. Ao se comparar a taxa de mortalidade por cor ano a ano, as etnias parda e branca tiveram taxas semelhantes entre 2004 e 2008. Excepcionalmente, em 2012, houve destaque para os indígenas, com taxa de 5,0 óbitos por 100 mil habitantes, que resultou no terceiro grupo de maior mortalidade nesse ano específico (Tabela 5). Destaca-se que a etnia/cor foi ignorada em 4.549 registros de óbitos (4,36\%).
Tabela 4. Óbitos por motos (número e taxa de mortalidade por 100 mil habitantes) segundo sexo e ano (Brasil, 2004 a 2014)

\begin{tabular}{|c|c|c|c|c|}
\hline \multirow{2}{*}{ Ano } & \multicolumn{2}{|c|}{ Masculino } & \multicolumn{2}{|c|}{ Feminino } \\
\hline & $\mathrm{N}^{\mathrm{o}}$ & Taxa & $\mathrm{N}^{\mathrm{o}}$ & Taxa \\
\hline 2004 & 4611 & 5,1 & 456 & 0,5 \\
\hline 2005 & 5367 & 5,8 & 628 & 0,7 \\
\hline 2006 & 6487 & 7,0 & 711 & 0,8 \\
\hline 2007 & 7251 & 7,7 & 866 & 0,9 \\
\hline 2008 & 7981 & 8,4 & 937 & 1,0 \\
\hline 2009 & 8336 & 8,7 & 968 & 1,0 \\
\hline 2010 & 9706 & 10,0 & 1188 & 1,2 \\
\hline 2011 & 10288 & 10,5 & 1196 & 1,2 \\
\hline 2012 & 11173 & 11,3 & 1369 & 1,4 \\
\hline 2013 & 10755 & 10,8 & 1285 & 1,3 \\
\hline 2014 & 11284 & 11,3 & 1365 & 1,3 \\
\hline Média & 8476,3 & 8,8 & 997,2 & 1,0 \\
\hline $\begin{array}{l}\text { IC95\% } \\
\text { média }\end{array}$ & $7084,4-9868,2$ & $7,5-10,1$ & $813,6-1180,8$ & $0,85-1,18$ \\
\hline
\end{tabular}

Dez óbitos com sexo ignorado; p-valor (teste $\mathrm{F}$ de igualdade das médias do número) < 0,001; $\mathrm{p}$-valor (teste $\mathrm{F}$ de igualdade das médias das taxas) $<0,001$. Fonte: Brasil ${ }^{14}$, Instituto Brasileiro de Geografia e Estatística ${ }^{15}$

Predominou a escolaridade de 4 a 7 anos, seguida de 8 a 11 anos de estudo, e cada uma dessas faixas corresponde a aproximadamente $30 \%$ dos óbitos por acidentes envolvendo motocicletas entre 2004 e 2014 (Tabela 6). Ressalta-se que 4\% a 5\% dos indivíduos que vieram a óbito durante a condução de motocicletas entre 2004 e 2014 não possuíam nenhuma escolaridade. Os dados para escolaridade não foram apresentados na forma de taxa, pois a população brasileira não se encontra estratificada por escolaridade nos bancos de dados consultados, assim as informações contidas na Tabela 6 estão apresentadas em porcentagem do total de óbitos. 
Tabela 5. Óbitos por motos (número e taxa de mortalidade por 100 mil habitantes) segundo etnia/cor e ano (Brasil, 2004 a 2014)

\begin{tabular}{|c|c|c|c|c|c|c|c|c|c|c|}
\hline \multirow{2}{*}{ Ano } & \multicolumn{2}{|c|}{ Branca } & \multicolumn{2}{|c|}{ Preta } & \multicolumn{2}{|c|}{ Amarela } & \multicolumn{2}{|c|}{ Parda } & \multicolumn{2}{|c|}{ Indígena } \\
\hline & $\mathbf{N}^{\circ}$ & Taxa & $\mathbf{N}^{\circ}$ & Taxa & $\mathbf{N}^{\circ}$ & Taxa & $\mathbf{N}^{\circ}$ & Taxa & $\mathrm{N}^{\circ}$ & Taxa \\
\hline 2004 & 2553 & 2,7 & 207 & 1,9 & 29 & 3,8 & 1824 & 2,4 & 3 & 1,0 \\
\hline 2005 & 2927 & 3,2 & 232 & 2,0 & 13 & 1,5 & 2453 & 3,1 & 2 & 0,6 \\
\hline 2006 & 3645 & 3,9 & 291 & 2,2 & 13 & 1,4 & 2861 & 3,6 & 6 & 1,1 \\
\hline 2007 & 3997 & 4,3 & 348 & 2,5 & 16 & 1,6 & 3417 & 4,2 & 8 & 1,5 \\
\hline 2008 & 4261 & 4,6 & 400 & 3,1 & 15 & 1,4 & 3878 & 4,6 & 10 & 1,9 \\
\hline 2009 & 4226 & 4,5 & 455 & 3,4 & 10 & 1,1 & 4243 & 5,0 & 5 & 1,2 \\
\hline 2010 & 4689 & 5,0 & 508 & 3,4 & 22 & 1,0 & 5276 & 6,3 & 10 & 1,2 \\
\hline 2011 & 4789 & 5,1 & 619 & 3,8 & 13 & 1,2 & 5630 & 6,6 & 28 & 3,5 \\
\hline 2012 & 4885 & 5,3 & 604 & 3,8 & 16 & 1,5 & 6510 & 7,3 & 30 & 5,0 \\
\hline 2013 & 4945 & 5,3 & 552 & 3,4 & 25 & 2,6 & 6415 & 7,1 & 28 & 4,1 \\
\hline 2014 & 4662 & 5,1 & 676 & 3,9 & 18 & 1,8 & 6787 & 7,4 & 21 & 2,6 \\
\hline Média & 4143,5 & 4,5 & 444,7 & 3,0 & 17,3 & 1,7 & 4481,3 & 5,2 & 13,7 & 2,1 \\
\hline IC95\% média & $3668-4619,1$ & $3,94-4,97$ & $349,1-540,3$ & $2,60-3,49$ & $13,8-20,7$ & $1,24-2,20$ & $3449,6-5512,9$ & $4,17-6,29$ & $7,3-20,1$ & $1,29-3,00$ \\
\hline
\end{tabular}

4.549 óbitos com etnia/cor ignorada; $\mathrm{p}$-valor (teste $\mathrm{F}$ de igualdade das médias do número) < 0,001; p-valor (teste $\mathrm{F}$ de igualdade das médias das taxas) $<0,001$. Fonte: Brasil ${ }^{14}$, Instituto Brasileiro de Geografia e Estatística ${ }^{15}$

Tabela 6. Óbitos por motos (número e percentual) segundo escolaridade e ano (Brasil, 2004 a 2014)

\begin{tabular}{|c|c|c|c|c|c|c|c|c|c|c|}
\hline \multirow{2}{*}{ Ano } & \multicolumn{2}{|c|}{ Nenhuma } & \multicolumn{2}{|c|}{1 a 3 anos } & \multicolumn{2}{|c|}{4 a 7 anos } & \multicolumn{2}{|c|}{8 a 11 anos } & \multicolumn{2}{|c|}{12 anos ou mais } \\
\hline & $\mathbf{N}^{\circ}$ & $\%$ & $\mathbf{N}^{\circ}$ & $\%$ & $\mathbf{N}^{\circ}$ & $\%$ & $\mathbf{N}^{\circ}$ & $\%$ & $\mathbf{N}^{\circ}$ & $\%$ \\
\hline 2004 & 167 & 5,1 & 698 & 21,5 & 1131 & 34,8 & 954 & 29,4 & 297 & 9,1 \\
\hline 2005 & 1 & 0,0 & 798 & 21,2 & 1343 & 35,7 & 1239 & 33,0 & 378 & 10,1 \\
\hline 2006 & 216 & 4,6 & 849 & 18,1 & 1605 & 34,1 & 1552 & 33,0 & 479 & 10,2 \\
\hline 2007 & 228 & 4,2 & 952 & 17,7 & 1835 & 34,1 & 1812 & 33,6 & 562 & 10,4 \\
\hline 2008 & 259 & 4,2 & 952 & 15,3 & 2288 & 36,7 & 2151 & 34,5 & 577 & 9,3 \\
\hline 2009 & 263 & 4,0 & 1091 & 16,4 & 2467 & 37,1 & 2222 & 33,4 & 614 & 9,2 \\
\hline 2010 & 281 & 3,6 & 1293 & 16,4 & 2927 & 37,1 & 2571 & 32,6 & 812 & 10,3 \\
\hline 2011 & 347 & 4,0 & 1734 & 20,0 & 3076 & 35,5 & 2908 & 33,6 & 593 & 6,8 \\
\hline 2012 & 438 & 4,5 & 1972 & 20,2 & 3379 & 34,6 & 3396 & 34,7 & 594 & 6,1 \\
\hline 2013 & 470 & 5,0 & 1862 & 19,9 & 3195 & 34,2 & 3242 & 34,7 & 576 & 6,2 \\
\hline 2014 & 489 & 4,9 & 1931 & 19,4 & 3425 & 34,4 & 3498 & 35,1 & 616 & 6,2 \\
\hline Média & \multicolumn{2}{|c|}{287,2} & \multicolumn{2}{|c|}{1284,7} & \multicolumn{2}{|c|}{2424,6} & \multicolumn{2}{|c|}{2322,3} & \multicolumn{2}{|c|}{554,4} \\
\hline IC95\% & \multicolumn{2}{|c|}{$202,2-372,2$} & \multicolumn{2}{|c|}{$991,9-1577,5$} & \multicolumn{2}{|c|}{$1927,9-2921,4$} & \multicolumn{2}{|c|}{$1802,9-2841,7$} & \multicolumn{2}{|c|}{$474,9-633,8$} \\
\hline
\end{tabular}

p-valor (teste F de igualdade das médias) < 0,001; IC95\% refere-se ao intervalo de confiança da média. Fonte: Brasil ${ }^{14}$

De 2\% a 3\% dos óbitos entre 2004 e 2014 foram declarados como acidentes de trabalho (média de 264,2 acidentes por ano) e $26 \%$ a $40 \%$ foram declarados como não decorrentes de acidente de trabalho. Nesse contexto, ressalta-se que na maioria (57\% a 70\%) dos casos a condição de ser ou não acidente de trabalho não foi notificada (ignorada).

\section{DISCUSSÃO}

O presente estudo evidenciou que entre 2004 e 2014 houve tendência de crescimento significativa nas taxas de mortalidade envolvendo motociclistas, evidenciado pela comparação com a mortalidade em relação aos acidentes de transporte no Brasil (14,2\% para $27,9 \%$ ) ou pela tendência das taxas brutas e padronizadas de mortalidades entre motociclistas no Brasil (2,8 óbitos em 2004 para 6,2 óbitos por 100 mil habitantes em 2014).
No período, a população brasileira variou de 181.581 .024 para 202.768.562 habitantes, o que representou um aumento de $10,4 \%$. De acordo com esse resultado, a representatividade dos óbitos envolvendo motocicletas em relação aos óbitos causados pelas causas externas também foi aproximadamente o dobro e os motociclistas representaram aproximadamente $4 \%$ dos óbitos classificados como causas externas em 2004 e 7,9\% em 2014.

Na Região das Américas, com exceção dos Estados Unidos, segundo a ordem, os principais vulneráveis no trânsito são pedestres, motociclistas e ciclistas ${ }^{1}$. Diferentemente, no Brasil, os motociclistas assumem o maior risco ${ }^{18}$. Além disso, o índice de fatalidade na circulação viária brasileira é considerado um dos mais altos do mundo ${ }^{7,19}$. Aproximadamente $62 \%$ das vítimas fatais de acidentes de trânsito são procedentes de dez países, elencados conforme a magnitude: Índia, China, Estados Unidos, 
Rússia, Brasil, Irã, México, Indonésia, África do Sul e Egito. Esses países são responsáveis por $56 \%$ da população mundial ${ }^{1}$.

Nesse sentido, destaca-se que a história do trânsito no Brasil foi traçada pela adaptação irresponsável das vias e cidades à extrema utilização de veículos motores. As condições atuais de mobilidade de pessoas e mercadorias nas grandes cidades foram influenciadas por inúmeras decisões políticas públicas. Em especial a partir dos anos 50, ocorreu a reconfiguração do espaço nacional que passou a ser acessível por uma rede de rodovias, com impacto econômico positivo. Na década de 1980, houve a massificação do uso da motocicleta, sendo considerada uma fase de motorização irresponsável da sociedade brasileira, destinada aos grupos sociais de baixa renda ${ }^{2,3}$. Em contraposição, não existe um estudo abrangente que compare os resultados que teriam sido obtidos com a expansão do sistema ferroviário ${ }^{3}$.

As maiores variações médias de mortalidade entre motociclistas em relação aos acidentes de transporte encontram-se nas macrorregiões mais vulneráveis, como Nordeste, Norte e Centro-Oeste. Morais et al. ${ }^{6}$ concluíram que o maior risco de morte por acidente de trânsito ocorreu nos municípios de 20 a 100 mil habitantes. Os acidentes de trânsito ocorrem de forma dispersa pelo território brasileiro, no entanto as mortes acontecem principalmente em localidades que não reconhecem o problema, cortadas por vias expressas, estradas movimentadas em má conservação, principalmente em cidades em crescimento, onde os veículos circulam com pouca ou sem fiscalização e sinalização ${ }^{20}$.

Pela apreciação das taxas brutas e padronizadas de mortalidade entre motociclistas, é possível afirmar, sequencialmente, que as maiores taxas encontram-se nas macrorregiões Centro-Oeste, Nordeste e Norte. A forte associação entre o rápido aumento da frota de motocicletas com o incremento nas taxas de óbitos - mais significante no Norte, Centro-Oeste e Nordeste - relaciona-se com esses resultados. $\mathrm{O}$ aumento crescente na frota de motocicletas, sem a correspondência de normas claras para sua movimentação e segurança, constitui um problema a mais para a mobilidade social ${ }^{20}$.

As principais vítimas da violência no trânsito motociclístico são jovens do sexo masculino - 20 a 39 anos -, com destaque para o grupo etário de 20 a 29 anos. De forma geral, salienta-se que as violências são fenômenos complexos, multicausais, com raízes em fatores sociais, culturais, políticos e econômicos, sendo o sexo masculino o mais vulnerável, seja como autor, seja como vítima ${ }^{21}$.

Os padrões socioculturais relacionados às questões de gênero se perpetuam na sociedade e determinam a vulnerabilidade entre homens jovens que estão no auge de suas potencialidades. Segundo o Ministério da Saúde ${ }^{21}$, os processos envolvidos na socialização contribuem para justificar a maior exposição do sexo masculino às violências, vinculada ao uso abusivo de álcool e drogas ilícitas.
A naturalização da violência do espaço público - violência da sociabilidade - faz com que os comportamentos violentos nem sejam percebidos como tais, sendo imprescindível abordar a questão de modo explícito. Existe, então, uma pressão social machista que impulsiona o sexo masculino a situações de risco ${ }^{19}$.

A baixa escolaridade é uma característica que acompanha as vítimas do trânsito motociclístico, inferida pela maior média no grupo de 4 a 7 anos de escolaridade - baixo nível escolar. As menores médias foram observadas entre aqueles que não tinham nenhuma escolaridade - analfabetos - e entre os que tinham acima de 12 anos de escolaridade - alto nível escolar. Nesse sentido, advoga-se que a rápida motorização brasileira repercutiu em sérias consequências em decorrência do baixo nível educacional da população, que interfere na capacidade de interpretar as informações sobre os riscos existentes; pela propaganda competente que idealiza a motocicleta como sinônimo de liberdade; pelo silêncio da indústria a respeito dos problemas de segurança dos veículos ${ }^{2,4}$.

Houve uma média anual de 287 casos de óbitos entre motociclistas analfabetos. No país, o índice de analfabetismo ainda é elevado, fator que impossibilita a aquisição da habilitação de motociclista e aumenta o risco de acidentes para o condutor. Um estudo realizado no Ceará evidenciou que 51,6\% das vítimas não possuíam habilitação e eram, em sua maioria, procedentes do interior do estado, sobretudo por não haver fiscalização intensa nessas localidades. A falta de qualificação para a condução do veículo - conhecimento sobre direção defensiva, principais causas de acidentes, equipamentos de segurança e legislação específica - acabará desprovendo o motociclista de habilidades para se livrar dos perigos ${ }^{19}$.

A maior média de óbitos concentrou-se na etnia/cor parda. Esse fenômeno não atinge somente o Brasil, mas também outros países da América Latina ${ }^{22}$. Chamou atenção a média das taxas de óbitos de indígenas ultrapassar a etnia/cor amarela, fato que merece um estudo mais detalhado que motive uma postura protetiva dos povos indígenas. Destaca-se que a etnia/cor foi ignorada em 4,4\% dos registros de óbitos, o que torna imprecisos os resultados apresentados.

Evidenciou-se que a maioria das notificações de óbitos entre motociclistas desconsiderou a informação que trata da presença ou não de acidente de trabalho. Sabe-se que o baixo preço da motocicleta, a maior flexibilidade no trânsito e a deficiência na regulamentação e fiscalização contribuíram para o seu uso como meio de trabalho-renda ${ }^{4}$.

No mercado informal de trabalho brasileiro, uma das profissões que mais crescem é a dos motociclistas profissionais - motoboys e mototáxis. Em um estudo realizado por Amorim et al. ${ }^{23}$, observou-se em uma amostra de 300 participantes que a maioria dos profissionais mototaxistas $(89,5 \%)$ não possuía outra atividade remunerada, bem como não contribuía para a Previdência Social (76,8\%). Diante dessa questão, Mello Jorge ${ }^{18}$ 
sinaliza que, nos municípios nos quais houve liberação para o exercício de mototáxis, as taxas de morbimortalidade do grupo sofreram grande aumento.

A negligência quanto à notificação de acidentes de trabalho promove imprecisão dos resultados apresentados e contribui com a manutenção do trabalho informal e das condições inadequadas para o trabalho sobre duas rodas. Os motoboys e mototaxistas são mais suscetíveis a sofrer acidentes por sua maior exposição em vias públicas, em razão de suas atividades: realizam elevado número de entregas em curto espaço de tempo, sofrem pressão dos clientes, trabalham com precárias condições e relações de trabalho - pagamento por produção -, péssimas condições do veículo e das vias ${ }^{2,23,24}$, sofrem desgaste físico e emocional, entre outros ${ }^{23}$.

Ademais, houve aumento expressivo na frota de motocicletas no Brasil com evidência de forte correlação com o incremento nas taxas de mortalidade entre motociclistas. $\mathrm{O}$ mesmo padrão de correlação seguiu entre todas as grandes regiões geográficas, com destaque para as regiões mais vulneráveis economicamente, como Norte, Nordeste e Centro-Oeste.

Em relação à influência da dimensão político-econômica, destaca-se o apoio fiscal do governo federal à indústria automotiva. Exemplifica-se com a instalação da primeira fábrica da Honda na Zona Franca de Manaus, em 1978, e o aumento acelerado dos veículos após a liberação da importação das motocicletas em 1991, principalmente dos Estados Unidos e Japão ${ }^{2,3}$.

O processo de liberalização econômica, o Plano Real e as amplas privatizações que abarcaram a área de transporte público a partir de 1994 atuaram como força motriz de valorização da motocicleta no país ${ }^{3}$. Ocorreram, na década de 90, um aumento de 12 vezes nas vendas anuais e o incremento da frota nacional de 2 milhões em 1992, 11 milhões em $2008^{2}$ e mais de 24 milhões em $2015^{17}$.

Existe um forte estímulo à aquisição da motocicleta, não só em razão de seu baixo custo, mas principalmente pelas facilidades oferecidas para o seu pagamento, o que resulta em uma frota cada vez maior ${ }^{18}$. Observa-se uma forte ideologia de mercado estabelecida com a evidente ideia de que o transporte individual deva triunfar sobre o transporte coletivo, o que impacta diretamente na mobilidade e na segurança viária ${ }^{3}$.

Diante do exposto, é possível afirmar que o Brasil vive as consequências da motorização irresponsável de sua população e os acidentes motociclístico têm determinado um importante impacto com custos socioeconômicos e emocionais incalculáveis para as vítimas, familiares e o Estado ${ }^{2,22}$.

Informações do Global Status Report on Road Safety ${ }^{1}$ mostram que alguns dos veículos vendidos em $80 \%$ dos países do mundo não cumprem as normas básicas de segurança, particularmente em países pobres e de economia em desenvolvimento. A indústria de motocicletas sempre evitou discutir a insegurança do seu produto e procurou afastá-lo de uma imagem negativa, comportamento que imita o de outros produtores de bens que podem causar danos - como a indústria de fumo e de bebidas -, e usa o mesmo argumento de que "vende o que as pessoas querem comprar" ${ }^{2,7}$.

Atualmente, os projetos brasileiros de segurança e prevenção de acidentes de trânsito têm como pilares a educação, a engenharia e a fiscalização no trânsito, com estratégias de intervenção que focam apenas nos usuários do espaço viário - pedestres e condutores ${ }^{3,7,13}$. São exemplos de modificação de comportamento dos usuários pela aplicação conjunta dos pilares: uso do capacete, respeito à travessia de pedestres e a não ingestão de bebidas alcoólicas pelos condutores.

Ocorre, então, o predomínio de uma metodologia de análise da segurança comportamental que resulta na responsabilização individual do condutor e ignora toda a complexidade dos fatores sociais, econômicos e culturais que determinam a insegurança no trânsito ${ }^{7,25}$

A violência no trânsito não é uma doença para a qual se tem um remédio específico, pois se encontra inserida como parte das relações humanas e da dinâmica da sociedade. Para o estudo de possíveis soluções, depara-se com um acometimento multifacetado, no qual intervêm fatores de variadas naturezas, que necessitam de uma efetiva abordagem intersetorial ${ }^{4}$.

O Word Report on Road Traffic Injury Prevention ${ }^{26}$ conclama para que se efetive a intersetoridade na gestão de políticas públicas de redução de agravos no trânsito, com o efetivo envolvimento do setor de transportes, segurança viária, infraestrutura viária, regulação do mercado de veículos, planejamento urbano, entre outros.

Observou-se uma tendência crescente nos registros de óbitos de motociclistas decorrentes da violência no trânsito, além da confirmação da forte associação entre o aumento da frota de motocicletas e o incremento nas taxas de mortalidades.

Algumas características sobre o perfil dos usuários de motocicletas estimulam a reflexão sobre a perda do status inerente à vulnerabilidade humana ${ }^{27}$, remetendo-os ao status de condutores suscetíveis ao agravo. O perfil demográfico das vítimas fatais de acidentes de trânsito motociclísticos no Brasil pode estar diretamente relacionado à presença de exclusão social. O perfil dos óbitos segue o padrão observado na literatura: homens jovens, do sexo masculino e com baixa escolaridade. Além disso, a negligência ante a notificação da presença de acidentes de trabalho entre os óbitos aumenta a vulnerabilidade dos motociclistas e, consequentemente, contribui com as condições inadequadas para o trabalho sobre duas rodas.

Contudo, advoga-se que a abordagem intersetorial é o caminho para enfrentar os acidentes de trânsito motociclístico e o foco das intervenções de segurança no trânsito deve ampliar seu universo de análise para ir além das medidas de prevenção dos condutores de veículos e pedestres. 


\section{REFERÊNCIAS}

1. World Health Organization. Global Status Report on Road Safety 2013: supporting a decade of action, 2011-2020. Switzerland: WHO; 2013.

2. Vasconcellos EA. O custo social da motocicleta no Brasil. Rev Transportes Publicos [Internet]. 2008;30-31:127-42 [citado em 2017 jul 7]. Disponível em: http://apatru.org.br/arquivos/\%7B119C97E2-4817-4324-B4C8978DC4F1A446\%7D_revista-da-antp-119-20-artigo-eduardo-vasconcellos. pdf

3. Vasconcellos EA. Políticas de transporte no Brasil: a construção da mobilidade excludente. São Paulo: Manole; 2013.

4. Silva PHNV, Lima MLC, Moreira RS, Souza WV, Cabral APS. Estudo espacial da mortalidade por acidentes de motocicleta em Pernambuco. Rev Saude Publica. 2011;45(2):409-15. http://dx.doi.org/10.1590/S003489102011005000010. PMid:21344120.

5. Organização Mundial da Saúde. Classificação Estatística Internacional de doenças e problemas relacionados à saúde. Décima Revisão (CID-10). 8. ed. São Paulo: EDUSP; 2000.

6. Morais OL No, Montenegro MMS, Monteiro RA, Siqueira Júnior JB, Silva MMA, Lima CM, et al. Mortalidade por acidentes de transporte terrestre no Brasil na última década: tendência e aglomerados de risco. Ciênc. Saúde Colet. 2012;17(9):2223-36. http://dx.doi.org/10.1590/S141381232012000900002

7. Silva PHNV. Violência e morte no trânsito: associações ignoradas na prevenção dos acidentes com motociclistas. Recife: Editora Universitária UFPE; 2013.

8. Associação Brasileira dos Fabricantes de Motocicletas. Dados do setor [Internet]. São Paulo: ABRACICLO; 2017 [citado em 2017 jul 7]. Disponível em: http://abraciclo.com.br/index.php?option=com_content\&view=categ ory\&layout $=$ blog\&id $=21 \&$ Itemid $=37$

9. Irdesel J, Aydiner SB, Akgoz S. Rehabilitation outcome after traumatic brain injury. Neurocir. 2007;18(1):5-15. http://dx.doi.org/10.1016/S11301473(07)70303-2. PMid:17393041.

10. Beck LF, Dellinger AM, Oneil MEO. Motor vehicle crash injury rates by mode of travel, United States: using exposure-based methods to quantify differences. Am J Epidemiol. 2007;166(2):212-8. http://dx.doi.org/10.1093/ aje/kwm064. PMid:17449891.

11. Vieira RC, Hora EC, Oliveira DV, Vaez AC. Levantamento epidemiológico dos acidentes motociclísticos atendidos em um centro de referência ao trauma de Sergipe. Rev Esc Enferm USP. 2011;45(6):1359-63. http://dx.doi. org/10.1590/S0080-62342011000600012. PMid:22241193.

12. Ferreira TFA, Nápolis ACR, Lima CS, Araújo LC, Garcia CB, Lima PS, et al. Estudo da gravidade dos pacientes vítimas de acidentes de trânsito atendidos pelo Hospital de Clínicas de Uberlândia de dezembro de 2005 a março de 2006, segundo índices de trauma. Biosci J. 2009;25(2):152-60.

13. Morais OL No, Silva MMA, Lima CM, Malta DM, Silva JB Jr. Projeto Vida no Trânsito: avaliação das ações em cinco capitais brasileiras, 2011-2012. Rev. Epidemiol Serv Saude. 2013;22(3):373-82. http://dx.doi.org/10.5123/ S1679-49742013000300002.
14. Brasil. Ministério da Saúde. Informações de saúde DataSUS [Internet]. Brasília: Ministério da Saúde; 2017 [citado em 2017 jul 7]. Disponível em: http://tabnet.datasus.gov.br/cgi/deftohtm.exe?sim/cnv/pext10uf.def

15. Instituto Brasileiro de Geografia e Estatística. População residente enviada ao Tribunal de Contas da União 2001-2015 [Internet]. Rio de Janeiro: IBGE; 2017 [citado em 2017 jul 7]. Disponível em: http://www.ibge.gov.br/home/ estatistica/populacao/estimativa2015/serie_2001_2015_tcu.shtm

16. Bussab WO, Morettin PA. Estatística básica. 8. ed. São Paulo: Saraiva; 2013

17. Brasil. Ministério das Cidades. Departamento Nacional de Trânsito. Registro Nacional de Veículos Automotores [Internet]. Brasília: DENATRAN; 2017 [citado em 2017 jul 7]. Disponível em: http://www.denatran.gov.br/frota. htm

18. Mello Jorge MHP. Mortes de motociclistas ultrapassam as de pedestres no Brasil. Rev Abramet. 2012;29(1):32-5.

19. Andrade LM, Lima MA, Silva CHC, Caetano JA. Acidentes de motocicleta: características das vítimas e dos acidentes em hospital de Fortaleza, Brasil. Rev RENE. 2009;10(4):52-9.

20. Minayo MCS. Seis características das mortes violentas no Brasil. Rev Bras Estud Popul. 2009;26(1):135-40. http://dx.doi.org/10.1590/S010230982009000100010.

21. Brasil. Ministério da Saúde. Política Nacional de Saúde do Homem. Brasília: Ministério da Saúde; 2008.

22. Matos KF, Martins CBG. Mortalidade por causas externas em crianças, adolescentes e jovens: uma revisão bibliográfica. Espaç. Saúde. 2013;14(12):82-93.

23. Amorim CR, Araújo EM, Araújo TM, Oliveira NF. Acidentes de trabalho com mototaxistas. Rev Bras Epidemiol. 2012;15(1):25-37. http://dx.doi. org/10.1590/S1415-790X2012000100003. PMid:22450490.

24. Ganne N. Estudo sobre acidentes de trânsito envolvendo motocicletas na Cidade de Corumbá e região, Estado do Mato Grosso do Sul, Brasil, no ano de 2007. Rev. Pan. Amaz. Saúde. 2010;1(3):19-24.

25. Gunther H, Neto I. Comportamento no trânsito: uma perspectiva da psicologia ambiental. In: Gunther H, Cristo F, Feitosa ZO, editores. Pesquisas sobre comportamento no trânsito. São Paulo: Casa do Psicólogo; 2015.

26. World Health Organization. Word report on road traffic injury prevention. Switzerland: WHO; 2004

27. Corgozinho MM, Oliveira AAS. Equidade em saúde como marco ético da bioética. Saude Soc. 2016;25(2):431-41. http://dx.doi.org/10.1590/S010412902016153764
Recebido em: Maio 23, 2017 Aprovado em: Fev. 03, 2018 